\title{
ASSESSMENT OF POWER QUALITY INDICES OVER A DECADE OF CONTROL IN ARGENTINIAN DISTRIBUTION SYSTEM
}

\author{
Pedro Issouribehere, Juan Barbero, Gustavo Barbera, Fernando Issouribehere, IEEE Member, and Hugo Mayer
}

\begin{abstract}
The electricity distribution service in the Buenos Aires metropolitan area of Argentina, which was privatized in the early nineties, is carried out by three different Utilities and the control is performed by a Regulatory Agency (ENRE).

By the time this control began, the existing limits in IEC standards for Power Quality were adopted in order to obtain a starting point for the local regulation. In addition, the equipment employed to perform the measurements also meets IEC standards.

The aspects of Power Quality which are regulated, and therefore controlled, are voltage magnitude, voltage disturbances - harmonic distortion and flicker - , and long-term interruptions - 3 minutes or longer duration -. In every site in which the limits established for Power Quality are exceeded, the Utility is penalized.

The aim of the article is to show the results obtained over more than 10 years of permanent control. The carried out studies mainly consisted of processing the data collected since the beginning of the control in order to obtain: disturbance trends over the years, comparisons of the levels measured in different Utilities as well as disturbance behaviors throughout the day. In addition to this, the degree of fulfillment achieved by the Utilities is also assessed.
\end{abstract}

Index Terms - Flicker. Harmonics. Interruptions. Total Harmonic Distortion. Short-term flicker severity. Voltage Magnitude.

\section{INTRODUCTION}

$\mathrm{T}$ he electricity distribution service in Buenos Aires Argentina - is provided by three private companies and the control is carried out by the Regulatory Agency (ENRE). The IITREE of La Plata University provides technical assistance to the Regulatory Agency.

Table I summarizes information about each Utility, hereinafter named $\mathrm{A}, \mathrm{B}$ and $\mathrm{C}$.

Table I: Information of each Utility.

\begin{tabular}{|c|c|c|c|}
\hline Utility & Customers & $\begin{array}{c}\text { Supplied Energy } \\
{[\mathbf{G W h} \text { per year] }}\end{array}$ & $\begin{array}{c}\text { Area } \\
{\left[\mathbf{k m}^{2}\right]}\end{array}$ \\
\hline A & 300,000 & 2,600 & 5,700 \\
\hline B & $2,200,000$ & 16,600 & 3,300 \\
\hline C & $2,500,000$ & 17,900 & 4,600 \\
\hline
\end{tabular}

Since the beginning of the privatization, extensive Monitoring Programs regarding Power Quality have been carried out.

The control of Power Quality, which is detailed in [1-2] began in the mid-nineties. For this reason, more than a decade of permanent control has been achieved so far.

(*) P. Issouribehere, J. Barbero, G. Barbera, F. Issouribehere, and H. Mayer are with IITREE-LAT. Facultad de Ingeniería. Universidad Nacional de La Plata. (1900) 48 y 116. La Plata. Argentina (e-mail: iitree@iitree-unlp.org.ar).
Firstly, regarding Voltage Magnitude control, the RMS value is recorded in 15-minute intervals. A large Monitoring Campaign is conducted performing 670 weekly measurements per month. If it is detected that in certain site the recorded values are not within the permitted band, the Utility will be penalized. The fine will be imposed until the Utility shows by a new measurement that the problem has been fixed.

Then, the control of harmonics requires measuring the THD (Total Harmonic Distortion) and all the individual harmonics up to the $40^{\text {th }}$, as well. However, only the THD was used to assess harmonic behavior in several analyses carried out in the present article.

Regarding flicker control, the Pst (Short-term Flicker Severity) is employed. In all the studies carried out in the article concerning flicker phenomenon, the Pst parameter was used.

Each normalized weekly measurement consists of 1008 10minute intervals. To represent each measurement, either the mean value or the Percentile 95 (P95) of all the 10-min intervals was employed. This P95 represents that value exceeded by only $5 \%$ of all the 10-min intervals. This parameter is widely used in Argentinian regulations since it is the one to be compared to the established limits in order to determine whether a measurement is penalized or not.

Recent reports such as [3] of CIGRE/CIRED recommend using either P95 or P99 for each site in order to characterize the system. Since the P99 is not normally employed in Argentina, such a parameter was not used in this paper. Naturally, it would also be possible to represent the analyzed data by the P99 parameter.

The normalized equipment [4-5] is normally installed at the secondary of $\mathrm{MV} / \mathrm{LV}$ transformers. These points are not randomly chosen but are selected from the results obtained through a previous, massive survey that leads to localize those sites of the network which are more likely to have high levels of disturbances. This previous survey is carried out by using a large number of low-cost disturbance recorders that only provide the THD and a parameter similar to the Pst.

And last but not least, Utilities must also comply with maximum supply interruption rates, for long-term interruptions (duration longer than 3 minutes) imposed by Franchise Agreements.

In case of transgression of the limits the Utility must compute discounts (bonus) to the customers. These computations require the estimation of non-supplied energy, and for this reason network contingencies must be recorded.

The control method applied since 1997 provides deterministic information about long-term interruptions obtained with event recorders. 